\title{
Impaired T-Lymphocyte Proliferation Function in Biliary Atresia Patients With Chronic Cholestatic Jaundice After a Kasai Operation
}

\author{
JIA-FENG WU, BOR-LUEN CHIANG, HUEY-LING CHEN, HONG-SHEE LAI, MEI-HWEI CHANG, AND YEN-HSUAN NI \\ Departments of Pediatrics [J.-F.W., B.-L.C., H.-L.C., M.-H.C., Y.-H.N.] and Pediatric Surgery [H.-S.L.], National Taiwan University \\ Hospital, National Taiwan University, Taipei, Taiwan
}

\begin{abstract}
To investigate the association between chronic cholestatic jaundice, systemic immunity, and various infectious complications in patients with biliary atresia (BA), we performed a survey of the systemic immune function in 30 children with BA. Patients were divided into a jaundice group (total serum bilirubin $\geq 2 \mathrm{mg} / \mathrm{dL}$ for $>6 \mathrm{mo}$ ) and control group (total serum bilirubin $<2 \mathrm{mg} / \mathrm{dL}$ for $>6 \mathrm{mo}$ ) with comparable age. Patients were tested for serum immunoglobulin and complement levels, mitogen response, interleukin (IL)-4, IL-5, and interferon-gamma production after phytohemagglutinin (PHA) stimulation, blood cell and lymphocyte subpopulation counts, phagocytic function, and leukocyte adhesion complex. They were then followed prospectively for $6 \mathrm{mo}$, and severe infectious complications requiring hospitalization were recorded. Compared with jaundice-free patients, T-lymphocyte proliferation function, determined by PHA mitogen test was significantly lower $(p=0.02)$ in BA patients with chronic cholestatic jaundice after a Kasai operation. During the study period, patients with chronic cholestatic jaundice had a higher risk of severe infectious complications than their jaundice-free counterparts (risk ratio $=5.87 ; p=0.001$ ). In conclusion, BA patients with chronic cholestatic jaundice are associated with impairment of T-lymphocyte proliferation and increased incidence of severe infectious complications. (Pediatr Res 60: 602-606, 2006)
\end{abstract}

$\mathrm{B}$ A is one of the most common cholestatic liver diseases in early infancy. Early diagnosis with a prompt Kasai operative intervention before the age of $60 \mathrm{~d}$ is an important prognostic factor (1). However, about one third of patients with BA remain jaundiced even after prompt intervention, and in another one third of patients, jaundice reappears after recurrent episodes of ascending cholangitis (2). Increased susceptibility to various infectious pathogens has been noted in patients with cholestatic jaundice and cholestatic animal model (3-6). A previous study showed that the incidence of sepsis in jaundiced patients ranged from $25 \%$ to $72 \%$, and the mortality rate was around $20 \%$ to $30 \%$ (7). Infectious complications play an important role in the morbidity and mortality of jaundiced patients, although the exact mechanism of this

Received February 27, 2006; accepted July 4, 2006.

Correspondence: Yen-Hsuan Ni, M.D., Ph.D., Department of Pediatrics, National Taiwan University Hospital, No. 7, Chung-Shan S. Road., Taipei, Taiwan; e-mail: yhni@ha.mc.ntu.edu.tw.

The authors have no potential, perceived, or real conflicts of interest. Informed consent was obtained from each child's parents or guardian.

DOI: 10.1203/01.PDR.0000242270.91973.ff increased susceptibility to infectious pathogens remains largely unclear. Depressed systemic and local reticuloendothelial immune functions may be responsible for the susceptibility of these patients to infectious pathogens $(8,9)$. Impaired Kupffer cell phagocytic function and increased intestinal permeability to intestinal pathogens or endotoxins have been demonstrated in previous studies (10-13). Artificial bile duct ligation in animal models with short-term obstructive jaundice results in suppression of systemic immunity in rats and dogs (14-16). However, little is known about the association between chronic cholestatic jaundice and the systemic immune function in BA patients after a Kasai operation.

We conducted this study to evaluate the systemic immune function and infectious complications after a Kasai operation in BA patients.

\section{METHODS}

Subjects. From January 2004 to July 2005, this cross-sectional survey recruited 30 children with BA who underwent a Kasai operation (10 boys and 20 girls) at the Department of Pediatrics, National Taiwan University Hospital. The diagnosis of BA was established by intraoperative cholangiography. The ages at entry into the study ranged from 1 to $22.3 \mathrm{y}$ (median, 3.5). Patients with serum total bilirubin levels $>2 \mathrm{mg} / \mathrm{dL}$ for more than 6 mo were designated as the chronic cholestatic jaundice group. Twelve children (age range, 1-22.3 y; median, 1.8; three boys and nine girls) were noted to have serum total bilirubin levels $>2 \mathrm{mg} / \mathrm{dL}$ for $>6$ mo (range, 6-114) before enrollment in our study. Another 18 jaundice-free BA children (age range, 1-16.5 y; median, 4.6; seven boys and 11 girls) with serum total bilirubin levels $<2 \mathrm{mg} / \mathrm{dL}$ for $>6$ mo served as the control group (Table 1 ).

Ursodeoxycholic acid (UDCA) was prescribed to the majority of BA patients in our institute. Eleven $(91.7 \%)$ of the 12 jaundice patients and 14 $(77.8 \%)$ of the jaundice-free patients received UDCA therapy for $>3$ mo. There is no difference between these two groups in terms of UDCA use ( $p=$ 0.32). All patients were free of any immunosuppressant from at least $2 \mathrm{wk}$ before the study began until the end of the follow-up period. The immune studies would not be done until the patients were free of infection for at least 2 wk to avoid the possible confounding on systemic immune function. Nutritional assessment and blood sampling were performed at enrollment.

Hospitalization events due to various infectious complications such as pneumonia, cholangitis, peritonitis, urinary tract infection, bacteremia, and sepsis were defined as severe infectious complications. Patients were prospectively followed for $6 \mathrm{mo}$ after enrollment to record their infectious

Abbreviations: BA, biliary atresia; PHA, phytohemagglutinin; PMN, polymorphonuclear leukocyte; PWM, pokeweed mitogen; SI, stimulation index 
Table 1. General characteristics of the study population

\begin{tabular}{|c|c|c|c|c|c|}
\hline \multirow[b]{2}{*}{ Characteristics } & \multicolumn{2}{|c|}{$\begin{array}{l}\text { Jaundice group } \\
\quad(n=12)\end{array}$} & \multicolumn{2}{|c|}{$\begin{array}{l}\text { Nonjaundice group } \\
\quad(n=18)\end{array}$} & \multirow[b]{2}{*}{$p$} \\
\hline & Range & Median & Range & Median & \\
\hline \multicolumn{6}{|l|}{ Hemogram } \\
\hline WBC (cells $/ \mu \mathrm{L})$ & $2630-22,990$ & 7940 & $2510-11,990$ & 6860 & NS \\
\hline $\mathrm{Hb}(\mathrm{g} / \mathrm{dL})$ & $8.1-14.5$ & 11.6 & $7.5-14.4$ & 12.4 & NS \\
\hline \multicolumn{6}{|c|}{ Biochemical data $(\mathrm{mg} / \mathrm{dL})$} \\
\hline Albumin & $1.9-4.5$ & 3.6 & $3.1-4.5$ & 3.9 & NS \\
\hline Globulin & $1.6-4.7$ & 3.2 & $1.2-3.4$ & 2.8 & NS \\
\hline AST & $37-44$ & 219 & $20-338$ & 81 & 0.004 \\
\hline ALT & $33-387$ & 108 & $14-253$ & 81 & 0.05 \\
\hline Total bilirubin & $2.8-32$ & 14.8 & $0.2-1.8$ & 1 & 0.0000 \\
\hline \multicolumn{6}{|l|}{ Nutritional status* } \\
\hline Body weight & -4.5 to 1.26 & -0.8 & -0.83 to 1.54 & 0 & 0.003 \\
\hline Body length & -4.0 to 1.78 & -0.2 & -1.73 to 3.0 & 0 & NS \\
\hline TSF & -3.0 to 1.5 & -1.2 & -1.5 to 1.33 & -0.8 & NS \\
\hline MM & -4.51 to 2.34 & -1.2 & -2.21 to 1.82 & -0.21 & 0.0009 \\
\hline
\end{tabular}

* Profiles of nutritional status (including body weight, body length, triceps skinfold, and muscle mass) are presented as $z$ scores.

WBC, white blood cell; Hb, hemoglobin; ANC, absolute neutrophil count; AST, aspartate aminotransferase; ALT, alanine aminotransferase; GGT, $\gamma$-glutamyl transpeptidase; PT/INR, prothrombin time/international normalized ratio; TSF, triceps skinfold; MM, muscle mass; NS, not significant.

complications. Case mortality, liver transplantation, or the end of the scheduled 6-mo follow-up period, whichever came first, was defined as the endpoint of this study. This study was approved by the Institutional Review Board and Research Ethics Committee of National Taiwan University Hospital.

Blood analysis. Blood samples were collected to measure serum total and direct bilirubin, albumin, cholesterol, triglyceride, calcium, alanine aminotransferase, aspartate aminotransferase, $\gamma$-glutamyl transpeptidase, prothrombin time/international normalized ratio, serum total immunoglobulin ( $\mathrm{IgG}$, $\mathrm{IgA}$, and $\mathrm{IgM})$, complement ( $\mathrm{C} 3$ and $\mathrm{C} 4)$, peripheral white blood cell count, hemoglobin, platelet count, absolute neutrophil count, and absolute lymphocyte count. All blood samples were analyzed immediately after blood collection.

Nutritional assessment. Body weight, body length, mid-arm muscle mass derived from upper arm anthropometry, and mid-arm triceps skinfold were measured at enrollment. Each measurement was repeated 3 times, and the average value was recorded on source documents. Data on these measurements were translated into $z$ scores for further statistical analysis.

Mitogen assay. Lymphocyte proliferation was evaluated by mitogen assay using the mitogens PHA and pokeweed mitogen (PWM) as stimulants. PHA is a strong mitogen of T lymphocyte, and PWM is a mitogen for both T and B lymphocytes. Lymphocytes were isolated by centrifugation on FicollHypaque Density Medium (Pharmacia Ltd., Milton Keynes, UK) and diluted at a concentration of $2 \times 10^{6}$ cells $/ \mathrm{mL}$. These lymphocytes were then stimulated with PHA $(4 \mu \mathrm{g} / \mathrm{mL})$ and PWM $(4 \mu \mathrm{g} / \mathrm{mL})$. A control using RPMI 1640 was also added. All samples were run in triplicate, and the counts for the three measurements were averaged. Plates were incubated in a humidified incubator with $5 \% \mathrm{CO}_{2}$ at a temperature of $37^{\circ} \mathrm{C}$ for $54 \mathrm{~h}$. Blast transformation was labeled by $1 \mu \mathrm{Ci}\left[{ }^{3} \mathrm{H}\right]$-thymidine in culture for a further $18 \mathrm{~h}$. The cells were finally removed in FILTERMATE 196 Cell Harvester (Packard Instrument Co., Meriden, CT) onto filter papers. The incorporation of $\left[{ }^{3} \mathrm{H}\right]-$ thymidine was counted using the tritium window of a PACKARD Scintillation Counter Model 6400M (Packard Instrument Co.). The results were recorded in stimulation index (SI) as scintillation counts per minute of stimulant over control.

IL-4 chemiluminescent immunoassay. Supernatant of cell culture after PHA mitogen stimulant were collected at $54 \mathrm{~h}$ of stimulation for cytokines analysis. Human IL-4 Chemiluminescent Immunoassay (R\&D Systems, Inc., Minneapolis, MN) was applied for the quantitative determination of human IL-4 concentrations in cell culture supernates after $54 \mathrm{~h}$ of PHA stimulation. The concentration of IL-4 was determined by a luminometer (R\&D Systems, Inc.).
IL-5 and interferon-gamma (IFN- $\gamma)$ immunoassay. Supernatants at $54 \mathrm{~h}$ of cell culture of PHA mitogen studies were collected for cytokine analysis. Human IL-5 and IFN- $\gamma$ immunoassay (R\&D Systems, Inc.) were applied for the quantitative determination in cell culture supernatants after PHA stimulation.

Polymorphonuclear leukocyte (PMN) superoxide release chemiluminescent assay. Chemiluminescent qualitative assay was applied to investigate the superoxide release function of PMNs. Blood samples $(100 \mu \mathrm{L})$ were mixed with $200 \mu \mathrm{L}$ PMA $(10 \mu \mathrm{g} / \mathrm{mL})$ or $200 \mu \mathrm{L}$ normal saline, $200 \mu \mathrm{L}$ Luminol $\left(10^{-4} \mathrm{M}\right.$, Sigma Chemical Co., St. Louis, MO), and $500 \mu \mathrm{L}$ phosphatebuffered saline (PBS) containing azide $(0.05 \%)$ in activated and controlled tubes, respectively. Both activated and controlled specimens were counted by Luminometer (Bio-Orbit Oy, Turku, Finland)

Phagocytic function. A Phagotest was used to investigate the phagocytic function of granulocytes and monocytes. Whole blood samples $(200 \mu \mathrm{L})$ were incubated with fluorescein isothiocyanate (FITC)-labeled Escherichia coli (ORPEGEN Pharma Co., Heidelberg, Germany) in a $37^{\circ} \mathrm{C}$ warm water bath for $10 \mathrm{~min}$. They were then washed in PBS; red blood cell lyse was later added to lyse the red blood cells. The percentage of granulocyte and monocyte E. coli-FITC phagocytosis was determined by a flow cytometer (BD FACSCalibur, Becton Dickinson Co.).

Neutrophil basal CD11b/CD18 adhesion molecule expression. The baseline expression of $\mathrm{CD} 1 \mathrm{~b} / \mathrm{CD} 18$ leukocyte adhesion complex was determined by the following method: whole blood samples $(0.5 \mathrm{~mL})$ were incubated on ice with fluorescein-conjugated monoclonal antibody (MAb) to CD11b (Becton Dickinson Co.) and CD18 (IMMUNOTECH, Marseille, France) for 30 min. Lysing fluid was added; the tubes were incubated at room temperature for $10 \mathrm{~min}$ and then washed in PBS $(0.05 \%)$ and resuspended in PBSformaldehyde (1\%). All MAbs directed against leukocyte surface antigens were counted by a flow cytometer (BD FACSCalibur, Becton Dickinson Co.).

Lymphocyte subpopulation. Whole blood samples $(30 \mu \mathrm{L})$ were incubated with $5 \mu \mathrm{L}$ fluorescein-conjugated MAb to CD3, CD4, CD8, CD16, CD19, CD45, CD45RA, CD45RO, and CD56 antigens (Becton Dickinson Co.) in test tubes for $30 \mathrm{~min}$ for the analysis of lymphocyte subpopulations. Lysing solution $(50 \mu \mathrm{L})$ was added to the test tubes for another 30 min. Then $400 \mu \mathrm{L}$ double-distilled $\mathrm{H}_{2} \mathrm{O}$ was added for an additional $15 \mathrm{~min}$. All MAbs directed against lymphocyte surface antigens were counted by a flow cytometer (BD FACSCalibur, Becton Dickinson Co.).

Statistical analysis. Statistical analyses were performed with the use of the STATA statistical software package (StataCorp LP). The $z$ score was applied to the data management of nutritional status including body weight, body length, muscle mass derived from the mid-arm and triceps skinfold. Mann- 
Whitney $U$ test was applied for analysis of all continuous variables, and the Fisher exact test was used for categorical data. Backward stepwise multiple regression was applied to determine the association between different factors. A $p$ value $<0.05$ was defined as statistically significant.

\section{RESULTS}

All patients in this study group were diagnosed as BA by intraoperative cholangiography. Among these BA patients with chronic cholestatic jaundice $(n=12)$, five $(42 \%)$ of them had persistent jaundice after a Kasai operation, whereas the other seven $(58 \%)$ became jaundiced again after recurrent episodes of cholangitis. All patients in the control group $(n=$ 18) remained jaundice free after the Kasai operation.

In this study, there were eight children $(66.7 \%)$ between 1 and $5 \mathrm{y}$ old, three $(25 \%)$ between 5 and $10 \mathrm{y}$ old, and one $(2.3 \%)$ older than $10 \mathrm{y}$ in the jaundice study group $(n=12)$, whereas there were nine children (50\%) between 1 and $5 \mathrm{y}$ old, eight (44.4\%) between 5 and 10 y old, and one (5.6\%) older than $10 \mathrm{y}$ in the control group $(n=18)$. There was no difference between these two groups in age distribution $(p>$ $0.05)$.

Six $(50 \%)$ of the 12 patients in the jaundice group received liver transplant due to chronic liver insufficiency or uncontrolled esophageal variceal bleeding 3-4 mo (median, 3.5) after enrollment in our study. One patient $(8 \%)$ in the jaundice group died of Candida sepsis after 3.5 mo of follow-up. The follow-up period in the jaundice group ranged from 3 to 6 mo (median, 5). One child (6\%) in the nonjaundice control group received a liver transplant 4 mo after enrollment due to uncontrolled esophageal variceal bleeding. The follow-up period in the control group ranged from 4 to 6 mo (median, 6). No difference in the follow-up period was identified between these two groups $(p>0.05)$.

There were 11 severe infectious events in the 57 personmonths of follow-up in the jaundice group and three events in the 106 person-months of follow-up in the control group (Table 2). There were three episodes of sepsis in the jaundice group (one episode due to Candida albican and another two events due to E. coli). Sputum culture showed no bacterial pathogen in the five episodes of pneumonia. Viral isolation identified influenza $\mathrm{A}$ virus and adenovirus in two episodes among the four pneumonia events in the jaundice group. Blood culture in the five cholangitis events all failed to identify bacterial pathogen. Another patient in the jaundice group who suffered from an $E$. coli urinary tract infection was also identified. Patients with cholestatic jaundice had more

Table 2. Infectious complications in the study population

\begin{tabular}{lccccc}
\hline & $\begin{array}{c}\text { Jaundice } \\
\text { group }\end{array}$ & $\begin{array}{c}\text { Control } \\
\text { group }\end{array}$ & $\begin{array}{c}\text { Risk } \\
\text { difference }\end{array}$ & $95 \%$ CI & $p$ \\
\hline Sepsis & 3 & 0 & 0.136 & -0.01 to 0.28 & 0.0001 \\
Atypical pneumonia & 4 & 1 & 0.056 & -0.01 to 0.12 & 0.039 \\
Cholangiitis & 3 & 2 & 0.031 & -0.03 to 0.09 & NS \\
UTI & 1 & 0 & 0.017 & -0.02 to 0.05 & NS \\
Total events & 11 & 3 & 0.134 & 0.04 to 0.23 & 0.0013 \\
\hline
\end{tabular}

There were 57 person-months of follow-up in the jaundice group and 106 person-months of follow-up in the nonjaundice group.

UTI, urinary tract infection. severe infectious events than jaundice-free patients did (risk ratio: 5.87 ; $95 \%$ confidence interval $(\mathrm{CI}): 1.70-20.31 ; p=$ $0.001)$.

Serum levels of $\operatorname{IgG}$, IgA, and IgM were not statistically different between the jaundice and nonjaundice groups (Table 3). Serum IgG was found to be lower than age-matched normal values in Taiwan (17) in three patients $(25 \%)$ in the jaundice group $(n=12)$ and four patients $(22 \%)$ in the control group. There was no difference between these two groups (odds ratio: $1.12 ; 95 \%$ CI: $0.30-4.16 ; p=0.86$ ). During the follow-up period, two (29\%) of the seven patients whose serum IgG level below normal age-matched levels had infectious events. Compared with other 23 children with normal age-matched serum IgG levels in our study, these seven patients did not have clinical evidence of increased susceptibility to infectious complications (risk ratio: $0.73 ; 95 \% \mathrm{CI}$ : $0.20-2.62 ; p=0.62$ ).

Significant impairment of T-lymphocyte proliferation function was observed in the jaundice group compared with the nonjaundice group, as demonstrated by a lower SI ratio in the PHA $(p=0.02)$ mitogen stimulation test (Fig. 1A). There was a significant correlation between serum total bilirubin levels and the PHA SI ratio $(R=-0.38, p<0.05)$ in our study population (Fig. 1B).

Patients of BA with cholestatic jaundice were associated with lower $z$ scores in body weight $(p=0.003)$ and muscle mass $(p=0.0009)$ than jaundice-free patients in our study (Table 1). Hence, patients of BA with cholestatic jaundice were noted to have poor protein caloric status in our study. Muscle mass derived from upper arm anthropometry is considered to be a more reliable marker reflecting the nutritional status of protein as compared with body weight alone. To exclude the possible confounding effect of poor protein caloric status on T-lymphocyte proliferation, we applied backward

Table 3. Systemic humoral and cellular immunity of the study population

\begin{tabular}{|c|c|c|c|c|c|}
\hline & \multicolumn{2}{|c|}{$\begin{array}{l}\text { Jaundice group } \\
\quad(n=12)\end{array}$} & \multicolumn{2}{|c|}{$\begin{array}{l}\text { Nonjaundice group } \\
\quad(n=18)\end{array}$} & \multirow[b]{2}{*}{$p$} \\
\hline & Range & Median & Range & Median & \\
\hline \multicolumn{6}{|l|}{ Immunoglobulin } \\
\hline $\operatorname{IgG}(\mathrm{mg} / \mathrm{dL})$ & $529-2000$ & 1330 & $362-1862$ & 1000 & NS \\
\hline $\operatorname{IgA}(\mathrm{mg} / \mathrm{dL})$ & $36-518$ & 257 & $25-330$ & 146 & NS \\
\hline $\operatorname{IgM}(\mathrm{mg} / \mathrm{dL})$ & $59-396$ & 137 & $59-221$ & 123 & NS \\
\hline \multicolumn{6}{|l|}{ Complement } \\
\hline C3 (mg/dL) & $36-159$ & 99 & $66-150$ & 84 & NS \\
\hline $\mathrm{C} 4(\mathrm{mg} / \mathrm{dL})$ & $7-23$ & 14 & $8.2-20.9$ & 14 & NS \\
\hline \multicolumn{6}{|l|}{ Mitogen test (SI) } \\
\hline PHA & $1.0-64.8$ & 17 & $1.7-355$ & 144 & 0.02 \\
\hline PWM & $1-143$ & 17 & $1.7-158.8$ & 18.4 & NS \\
\hline \multicolumn{6}{|l|}{ Phagotest } \\
\hline Granulocyte (\%) & $48.3-91.3$ & 85 & $45-92.7$ & 83.5 & NS \\
\hline Monocyte (\%) & $26.4-85.5$ & 52 & $30.1-80.5$ & 59.6 & NS \\
\hline $\begin{array}{l}\text { Granulocyte } \\
\text { CD11b/18 (\%) }\end{array}$ & $98.3-100$ & 99.9 & $99.9-100$ & 100 & NS \\
\hline \multicolumn{6}{|l|}{ Cytokines (pg/mL) } \\
\hline IL-4 & $1.6-15$ & 4.3 & $1.6-84.9$ & 3.1 & NS \\
\hline IL-5 & $7.8-591.3$ & 44.1 & $7.8-477.3$ & 46.3 & NS \\
\hline IFN- $\gamma$ & $15.6-1900$ & 185.5 & $15.6-2047.6$ & 248.3 & NS \\
\hline
\end{tabular}

C3, complement 3; C4, complement 4. 

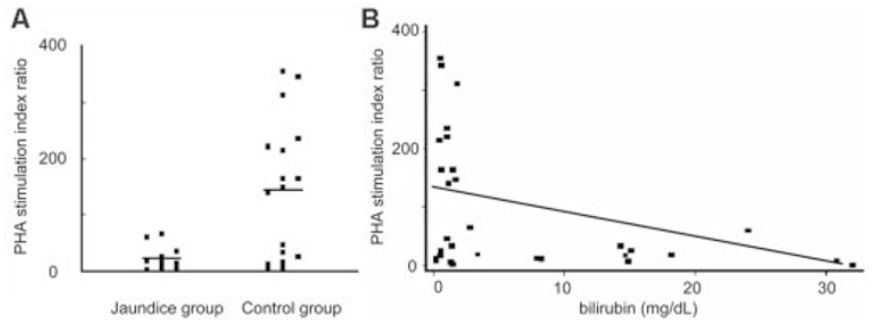

Figure 1. (A) PHA SI ratio is significantly lower in BA patients with chronic cholestatic jaundice $(n=12)$ as compared with the jaundice-free control group $(n=18 ; p=0.02)$. (B) Scatter plot demonstrates a significant correlation between serum total bilirubin level and PHA SI ratio $(n=30, R=$ -0.38 , adjusted $R^{2}=11.18 \%$, standard error $=2.40, p<0.05, \mathrm{Y}=126.85$ $-4.96 \mathrm{X})$.

stepwise multiple regression to analyze the correlation of serum total bilirubin and $z$ scores of muscle mass with the SI ratio for PHA mitogen stimulation test. A significant correlation between serum total bilirubin levels and PHA SI ratio was identified (correlation coefficient $=-4.96$; standard error $=$ 2.40; $p<0.05)$. Poor correlation between the $z$ scores of muscle mass and PHA SI ratio was also noticed.

The IL-4, IL-5, and IFN- $\gamma$ levels of cell culture supernatants after PHA mitogen stimulation showed no differences between BA patients with or without cholestatic jaundice (Table 3). Indicators of nonspecific cellular immunity, such as polymorphonuclear cell count and absolute cell count of each lymphocyte subpopulation, are summarized in Tables 3 and 4. No significant correlation of these aspects was observed in BA patients with cholestatic jaundice $(p>0.05)$.

\section{DISCUSSION}

We demonstrated significant impairment of T-lymphocyte proliferation function by PHA mitogen stimulation study in BA patients with chronic cholestatic jaundice after a Kasai operation. The detailed mechanism of suppressed Tlymphocyte proliferation is unclear $(13,18)$. Various plasma circulating inhibitory factors such as bile acids, cytokine, bilirubin, endotoxin, and lipoproteins are possible causes of T-lymphocyte defects (19). High serum bile acids have been

Table 4. Absolute lymphocyte subpopulation of the study

\begin{tabular}{|c|c|c|c|c|c|}
\hline \multirow[b]{2}{*}{$\mathrm{k} / \mu \mathrm{L}$} & \multicolumn{2}{|c|}{$\begin{array}{l}\text { Jaundice group } \\
\quad(n=12)\end{array}$} & \multicolumn{2}{|c|}{$\begin{array}{l}\text { Nonjaundice group } \\
\quad(n=18)\end{array}$} & \multirow[b]{2}{*}{$p$} \\
\hline & Range & Median & Range & Median & \\
\hline Total no. of lymphocytes & $807-10,460$ & 3775 & $590-6660$ & 3140 & NS \\
\hline $\mathrm{T}$ cell $\left(\mathrm{CD}^{+}\right)$ & $179-5034$ & 2239 & $370-4777$ & 1742 & NS \\
\hline $\mathrm{B}$ cell $\left(\mathrm{CD} 19^{+}\right)$ & $158-3908$ & 1019 & $82-1830$ & 530 & NS \\
\hline $\begin{array}{l}\text { Natural killer cell } \\
\left(\mathrm{CD} 16^{+} 56^{+}\right)\end{array}$ & $32-1513$ & 286 & $19-745$ & 270 & NS \\
\hline $\begin{array}{l}\text { Suppressor T cell } \\
\qquad\left(\mathrm{CD}^{+} 8^{+}\right)\end{array}$ & $66-1890$ & 630 & $126-1996$ & 611 & NS \\
\hline Helper $\mathrm{T}$ cell $\left(\mathrm{CD}^{+}{ }^{+}\right)$ & $123-3032$ & 1296 & $214-2406$ & 938 & NS \\
\hline $\mathrm{CD} 4^{+} / 8^{+}$ratio & $1.1-3.5$ & 1.8 & $0.8-3.7$ & 1.6 & NS \\
\hline $\begin{array}{l}\text { Naïve } T \text { cell } \\
\qquad\left(\mathrm{CD}^{+} 45 \mathrm{RA}^{+}\right)\end{array}$ & $54-2087$ & 862 & $117-1723$ & 665 & NS \\
\hline $\begin{array}{l}\text { Memory T cell } \\
\qquad\left(\mathrm{CD}^{+} 45 \mathrm{RO}^{+}\right)\end{array}$ & $68-964$ & 362 & $97-751$ & 326 & NS \\
\hline
\end{tabular}

shown to inhibit lymphocyte proliferation in a previous study (20). To minimize the effects of circulating factors in our study, we repeated cell washing during the processing of peripheral blood mononuclear cells for in vitro mitogen stimulation tests, removing most unbound plasma inhibitory factors. Fraser et al. (21) demonstrated no difference in Tlymphocyte function after 2 wk of bile duct ligation in dogs, whereas Roughneen et al. (15) showed significant impairment in T-lymphocyte proliferation after 3 wk of obstructive jaundice. Such phenomena further suggest that the time course of obstructive jaundice itself plays a key role in the $\mathrm{T}$ lymphocyte defect. Hence, our patients with chronic jaundice for $>6$ mo could demonstrate a more reliable effect of the cholestatic jaundice on $\mathrm{T}$ lymphocytes.

Chronic protein caloric malnutrition is another factor that possibly contributes to the suppression of $\mathrm{T}$ lymphocytemediated immune function. The defect of T-lymphocyte function was demonstrated by Roughneen et al. (15) in the absence of nutritional depletion in animal model. In our study, patients in the jaundice group had lower $z$ scores in body weight and muscle mass than patients in the control group. However, low protein-caloric nutritional status itself was not a confounding factor between T-lymphocyte defects and cholestatic jaundice in our study population by the analysis of backward stepwise multiple regression. These cholestatic BA patients received intensive nutritional support in our hospital. It is possible that the nutritional status of our patients was maintained to an extent that no significant related impact on T-lymphocyte function could be observed.

Defective PMN phagocytic function with obstructive jaundice and impaired PMN superoxide release function by bilirubin and bile acids challenge has been demonstrated in animal studies $(16,22)$. However, no PMN dysfunction, including superoxide release, phagocytic function, absolute neutrophil cell number, and proportion of basal expression of leukocyte adhesion molecule (CD11b/CD18 complex) was identified in our study. Previous studies were limited to animal models, and the short-term jaundice was induced by artificial bile duct ligation for 2 to $3 \mathrm{wk}$. The physiologic and anatomic differences, as well as the etiology of obstructive jaundice, between human and animal studies could account for the different results. On the other hand, the number of BA patients with persistent cholestatic jaundice was not large in our study and it is possible that in such a small sample size, some borderline deterioration in PMN-mediated immunity would not be detected.

We also compared the effect of activated T lymphocyte on humoral and nonspecific cellular immunity between BA patients with or without cholestatic jaundice by cytokines assay. IL-4 produced by activated T lymphocytes is known to modulate isotype switching, IgE production of B lymphocytes, differentiating precursor helper $\mathrm{T}$ lymphocytes from the type II helper $\mathrm{T}$ lymphocytes, which regulates humoral immunity and antibody production (23). IL-5, another cytokine produced by $\mathrm{T}$ lymphocytes, is also known to exert pleiotropic effects on B-lymphocyte and eosinophilic lineage (24). IFN- $\gamma$ influences the class of antibody produced by B lymphocytes, upregulates major histocompatibility complex antigens, and 
increases the efficacy of macrophages (25). The concentrations of IL-4, IL-5, and IFN- $\gamma$ of cell culture supernatants after PHA mitogen stimulation were not different between these two groups. Such a phenomenon suggests that the amounts of IL-4, IL-5, and IFN- $\gamma$ released by activated T lymphocytes on humoral and nonspecific cellular immunity between cholestatic and nonjaundiced BA patients are not different.

UDCA therapy has been shown to reduce aberrant HLA class I antigens on cell surfaces in a previous study, which could be a confounding factor in our study (26). At our institute, the majority of $\mathrm{BA}$ patients received long-term UDCA treatment. Because the percentages of patients on UDCA therapy were not different between these two groups, the effect of UDCA on systemic immune function in this study may be mitigated when we do the comparisons.

This study demonstrates a strong association between chronic cholestatic jaundice and infectious complications in BA patients. Impaired T-lymphocyte proliferation function was evident in BA patients with chronic cholestatic jaundice, which may related to the increased infectious events in chronic cholestatic BA patients.

\section{REFERENCES}

1. Hoofnagle JH 2004 Biliary Atresia Research Consortium (BARC). Hepatology 39:891

2. Taylor RM, Cheeseman P, Davenport M, Tizzard SA, Goldblatt D, Mieli-Vergani G, Hadzic N 2003 Humoral immunity in children with biliary atresia splenic malformation syndrome. Eur J Pediatr 162:539-540

3. Plusa S, Webster N, Primrose J 1996 Obstructive jaundice causes reduced expression of polymorphonuclear leukocyte adhesion molecules and a depressed response to bacterial wall products in vitro. Gut 38:784-787

4. Maggiore G, De Giacomo C, Scotta MS, Siena S, Maccario R, Vitiello A 1982 Cell-mediated immunity in children with chronic cholestasis. J Pediatr Gastroenterol Nutr 1:385-388

5. Çaglikülekçi M, Besirov E, Özkan H, Gündogdu H, Bakanay SM 2001 The effect of granulocyte colony stimulating factor on the immune parameters in experimental obstructive jaundice. Hepatogastroenterology 48:220-223

6. Yüceyar H, Kokuludag A, Coker A, Ersöz G, Keskinoglu A, Güler A, Cavusoglu H 1996 The serum levels of soluble interleukin-2 receptor levels in patients with obstructive jaundice. Hepatogastroenterology 43:949-953
7. Ball SK, Grogan JB, Collier BJ, Scott-Conner CE 1991 Bacterial phagocytosis in obstructive jaundice-a microbiologic and electron microscopic analysis. Am Surg 57:67-72

8. Greve JW, Gouma DJ, Soeters PB, Buurman WA 1990 Suppression of cellular immunity in obstructive jaundice is caused by endotoxins: a study with germ-free rats. Gastroenterology 98:478-485

9. Cainzos M, Alcalde JA, Potel J, Puente JL 1992 Hyperbilirubinemia, jaundice and anergy. Hepatogastroenterology 39:330-332

10. Sano T, Ajiki T, Takeyama Y, Kuroda Y 2004 Internal biliary drainage improves decreased number of gut mucosal T lymphocytes and MAdCAM-1 expression in jaundiced rats. Surgery 136:693-699

11. Drivas G, James O, Wardle N 1976 Study of reticuloendothelial phagocytic capacity in patients with cholestasis. BMJ 1:1568-1569

12. Welsh FK, Ramsden CW, MacLennan K, Sheridan MB, Barclay GR, Guillou PJ, Reynolds JV 1998 Increased intestinal permeability and altered mucosal immunity in cholestatic jaundice. Ann Surg 227:205-212

13. Parks RW, Halliday MI, McCrory DC, Erwin P, Smye M, Diamond T, Rowlands BJ 2003 Host immune responses and intestinal permeability in patients with jaundice. Br J Surg 90:239-245

14. Feduccia TD, Scott-Conner CE, Grogan JB 1988 Profound suppression of lymphocyte function in early biliary obstruction. Am J Med Sci 296:39-44

15. Roughneen PT, Gouma DJ, Kulkarni AD, Fanslow WF, Rowlands BJ 1986 Impaired specific cell-mediated immunity in experimental biliary obstruction and its reversibility by internal biliary drainage. J Surg Res 41:113-125

16. Roughneen PT, Drath DB, Kulkarni AD, Rowlands BJ 1987 Impaired nonspecific cellular immunity in experimental cholestasis. Ann Surg 206:578-582

17. Hsieh KH, Casazza LJ 1972 The development of serum immunoglobulins in normal Chinese children from birth to six years of age. Acta Paediatr Sinica 13:161-166

18. Thompson RL, Ranjbar S, Rowlands BJ 1993 T-lymphocyte transformation in experimental obstructive jaundice: the role of serum-suppressive factors. World J Surg 17:783-785

19. Thompson RL, Hoper M, Diamond T, Rowlands BJ 1990 Development and reversibility of T lymphocyte dysfunction in experimental obstructive jaundice. Br J Surg 77:1229-1232

20. Gianni L, Di Padova F, Zuin M, Podda M 1980 Bile acid-induced inhibition of the lymphoproliferative response to phytohaemagglutinin and pokeweed mitogen: an in vitro study. Gastroenterology 78:231-235

21. Fraser IA, Krakowka S, Ringler S, Carey LC, Ellison EC 1989 Lymphocyte function in obstructive jaundice. Am J Surg 157:405-408

22. Iwanaga M, Nakagawara A, Matsuo S, Ikeda K 1987 Impaired polymorphonuclear leukocyte function in biliary atresia: role of bilirubin and bile acids. J Pediatr Surg 22:967-972

23. Ruhl S, Pluznik DH, Feldman GM 1993 Soluble interleukin-4 receptor production by murine myeloid progenitor cells-induction by interleukin- 6 and interferon gamma. Cytokine 5:144-149

24. Mahanty S, Nutman TB 1993 The biology of interleukin-5 and its receptor. Cancer Invest 11:624-634

25. Reiter Z 1993 Interferon-a major regulator of natural killer cell-mediated cytotoxicity. J Interferon Res 13:247-257

26. Calmus Y, Gane P, Rouger P, Poupon R 1990 Hepatic expression of class I and class II major histocompatibility complex molecules in primary biliary cirrhosis: effect of ursodeoxycholic acid. Hepatology 11:12-15 